\title{
Differential Internalization of Thrombin-Derived Host Defense Peptides into Monocytes and Macrophages
}

\author{
Finja C. Hansen ${ }^{a} \quad$ Aftab Nadeem $^{\text {b, c }}$ Kathryn L. Browning ${ }^{d}$ Mario Campana $^{e}$ \\ Artur Schmidtchen ${ }^{a, f, g}$ Mariena J.A. van der Plas ${ }^{a, d}$ \\ aDivision of Dermatology and Venereology, Department of Clinical Sciences Lund, Lund University, Lund, Sweden; \\ ${ }^{b}$ Department of Microbiology, Immunology and Glycobiology (MIG), Institute of Laboratory Medicine, Lund \\ University, Lund, Sweden; 'Department of Molecular Biology, Umeå University, Umeå, Sweden; ' 'LEO Foundation \\ Center for Cutaneous Drug Delivery, Department of Pharmacy, University of Copenhagen, Copenhagen, Denmark; \\ eISIS Neutron and Muon Source, Rutherford Appleton Laboratory, Harwell, UK; fDermatology, Skåne University \\ Hospital, Lund, Sweden; ' $C$ Copenhagen Wound Healing Center, Bispebjerg Hospital, Department of Biomedical \\ Sciences, University of Copenhagen, Copenhagen, Denmark
}

\section{Keywords}

Bacterial infection $\cdot$ Host defense peptides · Thrombin · Clathrin-dependent endocytosis · Caveolin-dependent endocytosis · Lysosomes

\begin{abstract}
Proteolytic cleavage of thrombin generates C-terminal host defense peptides exerting multiple immunomodulatory effects in response to bacterial stimuli. Previously, we reported that thrombin-derived C-terminal peptides (TCPs) are internalized in monocytes and macrophages in a time- and temperature-dependent manner. In this study, we investigated which endocytosis pathways are responsible for the internalization of TCPs. Using confocal microscopy and flow cytometry, we show that both clathrin-dependent and clathrin-independent pathways are involved in the internalization of the prototypic TCP GKY25 in RAW264.7 and human monocyte-derived M1 macrophages, whereas the uptake of GKY25 in monocytic THP-1 cells is mainly dynamin-dependent. Internalized GKY25 was transported to endosomes and
\end{abstract}

karger@karger.com www.karger.com/jin

Karger"

BOPEN ACCESS
(C) 2021 The Author(s).

Published by S. Karger AG, Basel

This is an Open Access article licensed under the Creative Commons Attribution-NonCommercial-4.0 International License (CC BY-NC) (http://www.karger.com/Services/OpenAccessLicense), applicable to the online version of the article only. Usage and distribution for commercial purposes requires written permission. finally lysosomes, where it remained detectable for up to 10 h. Comparison of GKY25 uptake with that of the natural occurring TCPs HVF18 and FYT21 indicates that the pathway of TCP endocytosis is not only cell type-dependent but also depends on the length and composition of the peptide as well as the presence of LPS and bacteria. Finally, using neutron reflectometry, we show that the observed differences between HVF18 and the other 2 TCPs may be explained partially by differences in membrane insertion. Taken together, we show that TCPs are differentially internalized into monocytes and macrophages.

(c) 2021 The Author(s).

Published by S. Karger AG, Basel

\section{Introduction}

The serine protease thrombin plays a central role in wound healing and tissue regeneration. Although most known for converting fibrinogen into fibrin [1], thrombin and its derived peptides fulfill various other functions, such as the recruitment of inflammatory cells and 
the activation of platelets and endothelial cells [2]. Previously, we showed that the proteolytic cleavage of thrombin by neutrophil elastase results in the formation of thrombin-derived C-terminal peptides (TCPs), such as the $11 \mathrm{kDa}$ TCP96, that can bind to and form amorphous amyloid-like aggregates with both bacterial lipopolysaccharides (LPS) and Gram-negative bacteria $[3,4]$, and smaller TCPs of roughly $2 \mathrm{kDa}$, such as HVF18 (HVFRLKKWIQKVIDQFGE) that dampens inflammation $[3,5,6]$. Moreover, we found that both Pseudomonas aeruginosa [7] and Staphylococcus aureus [8] can mimic the formation of these smaller TCPs, leading among others to the release of the peptide FYT21 (FYTHVFRLKKWIQKVIDQFGE). The prototypic TCP GKY25 (GKYGFYTHVFRLKKWIQKVIDQFGE), like the naturally occurring HVF18 and FYT21, binds to LPS, although with a higher affinity $[9,10]$. This LPS binding, initially determined by peptide charge and electrostatic interactions, prevents Toll-like receptor 4 dimerization, thereby inhibiting the activation of transcription factors NF- $\mathrm{KB}$ and AP-1, and the following release of pro-inflammatory cytokines $[7,11]$. Additionally, we reported reduced pro-inflammatory responses to Gram-negative bacteria in monocytes and macrophages in vitro, while in vivo studies of LPS-induced septic shock in mice showed a reduction in pro-inflammatory cytokine release, as well as in excessive activation of coagulation, fibrin deposition, and leakage in lungs, together resulting in reduced mortality $[5,6,12]$. While investigating the modes of action of TCPs, we observed that they are bound to and internalized in THP-1 monocytes and RAW264.7 macrophages in a time- and temperature-dependent manner [7, 11 , although the exact uptake mechanism remains unknown.

It was recently reported that the host defense peptide (HDP) LL-37 is internalized into macrophages by both clathrin-mediated endocytosis (CME) and caveolin-mediated endocytosis pathways [13]. Moreover, it was shown for several cell-penetrating peptides that they also are internalized by both CME and caveolin-mediated endocytosis pathways $[14,15]$. Based upon these investigations, the aim of this study was to investigate if TCPs may enter monocytes and macrophages via similar pathways.

\section{Materials and Methods}

Peptides

The thrombin-derived peptides GKY25 (GKYGFYTHVFRLKKWIQKVIDQFGE), FYT21 (FYTHVFRLKKWIQKVIDQFGE), and HVF18 (HVFRLKKWIQKVIDQFGE) were synthesized by
Biopeptide Co., Inc., San Diego, CA, USA. The purity (>95\%) and molecular weight of these peptides were confirmed by MS analysis.

\section{Reagents}

DRAQ5 and NP-40 were purchased from Abcam, UK. Cholera toxin subunit B (recombinant, Alexa Fluor 488), LysoTracker Green DND 26, MitoTracker Green FM, ER-Tracker Blue-White DPX, CellLight late endosomes-GFP (BacMam 2.0), and pHrodo green E. coli BioParticles were obtained from Life Technologies, Denmark. Dansylcadaverine [16], chlorpromazine hydrochloride [17], and monensin sodium salt [18] inhibit CME, dynasore inhibits clathrin-coated vesicle formation [19], filipin III from Streptomyces filipinensis and nystatin inhibit caveolin-mediated endocytosis $[20,21]$, and cytochalasin B and latrunculin A inhibit actin polymerization $[22,23]$. All inhibitors and Escherichia coli (0111:B4) LPS ( 500,000 endotoxin $\mathrm{U} / \mathrm{mg}$ ) were purchased from Merck, USA.

\section{Cell Cultures}

RAW 264.7 cells (American Type Culture Collection [ATCC]) were cultured in DMEM (HyClone; GE Healthcare Life Science, Chicago, IL, USA) and THP-1 cells (ATCC) in RPMI 1640-GlutaMAX-I (Gibco; Life Technologies ltd, Inchinnan, UK); both media were supplemented with $10 \%(\mathrm{v} / \mathrm{v})$ heat-inactivated FBS (FBSi; Invitrogen, Waltham, MA, USA) and $1 \%(\mathrm{v} / \mathrm{v})$ antibiotic-antimycotic solution (AA; Invitrogen), at $37^{\circ} \mathrm{C}$ in $5 \% \mathrm{CO}_{2}$.

Human CD14+ monocytes were isolated from blood from healthy donors and incubated in RPMI 1640 medium with $2 \mathrm{mM}$ glutamax-I/glutamine (Gibco), 10\% (v/v) FBSi, and 1\% (v/v) AA. To obtain monocyte-derived pro-inflammatory macrophages (M1), primary monocytes were stimulated with $5 \mathrm{ng} / \mathrm{ml} \mathrm{GM-CSF}$ (Sigma) for 7 days at $37^{\circ} \mathrm{C}$ in $5 \% \mathrm{CO}_{2}$ as described previously [24].

\section{LDH Assay}

RAW 264.7 cells $\left(200 \mu \mathrm{L}\right.$ of $8 \times 10^{5}$ cells $\left./ \mathrm{mL}\right)$ and THP- 1 cells $\left(200 \mu \mathrm{L}\right.$ of $5 \times 10^{5}$ cells $\left./ \mathrm{mL}\right)$ were seeded in 96 -well plates and incubated with the indicated endocytic inhibitors in the presence or absence of GKY25 $(2 \mu \mathrm{M})$ for $2 \mathrm{~h}$ at $37^{\circ} \mathrm{C}$ in $5 \% \mathrm{CO}_{2}$. LDH release was measured using a lactic acid dehydrogenase-based Cytotoxicity Assay Kit (Merck) according to the manufacturer's instructions.

\section{SDS PAGE and Western Blot}

RAW264.7 cells $\left(4 \times 10^{5}\right.$ cells $\left./ \mathrm{mL}\right)$ in DMEM with $10 \% \mathrm{FBSi}$ and $1 \%$ AA were seeded in 6-well plates and incubated with GKY25 $(6 \mu \mathrm{M})$ for the indicated time points. In a separate set of experiments, RAW264.7 cells were treated with $6 \mu \mathrm{M}$ GKY25 for $1 \mathrm{~h}$, washed twice with DMEM, and incubation was continued for up to $72 \mathrm{~h}$. Following incubation, cells were washed with PBS, lysed on ice with NP-40 buffer, and centrifuged at $14,000 \mathrm{~g}$ for $20 \mathrm{~min}$ at $4^{\circ} \mathrm{C}$. Supernatant $(10 \mu \mathrm{L})$ was diluted in reducing Tricine SDS Sample Buffer and denatured for $5 \mathrm{~min}$ at $95^{\circ} \mathrm{C}$. Next, proteins and peptides were separated by electrophoresis on 10-20\% Tris-Tricine gels using $1 \mathrm{x}$ Tris-Tricine SDS running buffer at $100 \mathrm{~V}$ for 100 min. Gels and buffer were derived from Life Technologies. Subsequently, samples were transferred to a PVDF membrane using a Trans Blot Turbo system (Bio-Rad, USA) at $25 \mathrm{~V}$ for $10 \mathrm{~min}$. Membranes were blocked with 3\% nonfat dry milk in PBS containing $0.05 \%$ Tween-20 (PBST) at RT for $30 \mathrm{~min}$, incubated with polyclonal rabbit antibodies against the thrombin C-terminal epitope 
VFRLKKWIQKVIDQFGE (VFR17; Innovagen AB, Sweden) for 1 $\mathrm{h}$ at RT, followed by 3 times washing with PBST and incubation with swine anti-rabbit immunoglobulin-HRP-conjugated antibodies (1:1,000; Dako, Denmark) for $1 \mathrm{~h}$ at RT. After washing the membranes thrice with PBST, GKY25 was visualized with SuperSignal West Pico Chemiluminescent Substrate (Thermo Scientific, Denmark) using the ChemiDoc MP imaging system (Bio-Rad).

\section{Flow Cytometry Analysis}

RAW264.7 $\left(4.5 \times 10^{5}\right.$ cells $\left./ \mathrm{mL}\right)$ in DMEM and THP- 1 cells (5 $\times 10^{5}$ cells $/ \mathrm{mL}$ ) in RPMI medium were seeded in 12 -well plates ( 1 $\mathrm{mL})$ or 24 -well plates $(400 \mu \mathrm{L})$. After overnight incubation, cells were washed once with PBS and incubated with the indicated inhibitors for $30 \mathrm{~min}$ at $37^{\circ} \mathrm{C}$, followed by the addition of $2 \mu \mathrm{M}$ TAMRA-labeled GKY25 (T-GKY25), T-HVF18, or T-FYT21 (2 $\mu \mathrm{M})$ diluted in the cell medium containing $5 \% \mathrm{FBSi}$ for $1 \mathrm{~h}$ at $37^{\circ} \mathrm{C}$. In a different setup, the indicated TAMRA-labeled peptides were preincubated for $1 \mathrm{~h}$ with $E$. coli LPS $(10 \mathrm{ng} / \mathrm{mL})$ before being added to the cells for $1 \mathrm{~h}$ at $37^{\circ} \mathrm{C}$. Next, cells were washed twice and suspended in the DMEM or RPMI medium supplemented with $5 \%$ FBSi. Samples were measured using a FACSVerse system (BD, USA) and analyzed with FlowJo software (v10 Documentation).

\section{Internalization of GKY25 in RAW264.7 Cells}

RAW 264.7 cells or M1 macrophages were seeded in 8-well chamber slides $\left(200 \mu \mathrm{L}\right.$ of $5 \times 10^{5}$ cells $\left./ \mathrm{mL}\right)$ and incubated overnight at $37^{\circ} \mathrm{C}$ in $5 \% \mathrm{CO}_{2}$ to allow adherence. The following day, cells were incubated for $30 \mathrm{~min}$ with the indicated inhibitors followed by $1 \mathrm{~h}$ incubation with T-GKY25 $(2 \mu \mathrm{M})$, T-FYT21 $(2 \mu \mathrm{M})$, or T-HVF18 $(2 \mu \mathrm{M})$ pre-incubated for $1 \mathrm{~h}$ with E. coli LPS (10 ng/ $\mathrm{mL})$ or with E. coli BioParticles $(10 \mu \mathrm{g} / \mathrm{mL})$. In a different setting, unbound endocytic inhibitors were washed away before the addition of T-GKY25. For nucleus staining, DRAQ5 $(4 \mu \mathrm{M})$ was added 15 min before the end of the GKY25 incubation. After incubation, cells were washed with the cell culture medium and PBS at $37^{\circ} \mathrm{C}$. Finally, the medium containing 5\% FBSi was added, and the samples were placed in an environmental chamber $\left(37^{\circ} \mathrm{C}\right.$ and $\left.5 \% \mathrm{CO}_{2}\right)$ followed by live cell imaging with a Nikon $\mathrm{A} 1+$ confocal on a TiE inverted microscope (Nikon, Japan) with GaAsO detectors. Images were collected using a $20 \mathrm{x}$ and $60 \mathrm{x} / 1.4$ plan Apo $\lambda$ s lens. $\lambda_{\text {ex }}$ $=488 \mathrm{~nm}$ was selected for green-labeled $E$. coli BioParticles, $\lambda_{\mathrm{ex}}=$ $561 \mathrm{~nm}$ for T-GKY25, and $\lambda_{\mathrm{ex}}=640 \mathrm{~nm}$ for DRAQ5. Images were captured and processed using the NIS-Elements software (Nikon) and the ImageJ software (version 1.49q).

\section{Aggregation of GKY25}

T-GKY25 $(2 \mu \mathrm{M})$ and inhibitors, in DMEM, were incubated in 8 -well chamber slides for $1 \mathrm{~h}$ at $37^{\circ} \mathrm{C}$ in $5 \% \mathrm{CO}_{2}$. Samples were investigated directly at room temperature using a Nikon A1+ confocal on a TiE inverted microscope with $\mathrm{GaAsO}$ detectors.

\section{Colocalization of GKY25 in RAW264.7 Cells}

For colocalization experiments, RAW264.7 cells were seeded in 8 -well chamber slides $\left(200 \mu \mathrm{L}\right.$ of $5 \times 10^{5}$ cells $\left./ \mathrm{mL}\right)$. For endosome staining, cells were directly incubated with the BacMam 2.0 late endosome-GFP $(50 \mu \mathrm{L})$ for $16 \mathrm{~h}$. After overnight incubation, cells were washed once with DMEM and incubated with $2 \mu \mathrm{M} \mathrm{T-GKY25,}$ T-FYT2 1 or T-HVF18 diluted in DMEM for $1 \mathrm{~h}$ at $37^{\circ} \mathrm{C}$ in $5 \% \mathrm{CO}_{2}$. Subsequently, cells were incubated with LysoTracker (200 nM), MitoTracker (200 nM), ERTracker (800 nM), or Cholera Toxin subunit B $(1 \mu \mathrm{g} / \mathrm{mL})$ for 30 min. After 2 washing steps with DMEM, DMEM containing 5\% FBSi was added and samples were placed in an environmental chamber $\left(37^{\circ} \mathrm{C}\right.$ and $\left.5 \% \mathrm{CO}_{2}\right)$.

Colocalization of the TAMRA-labeled GKY25 with the individual trackers was detected using live cell imaging with a Nikon A1+ confocal on a TiE inverted microscope (Nikon, Japan) with GaAsO detectors. A 60 x/1.4 plan Apo $\lambda$ s lens was used. Colocalization of T-HVF18 and T-FYT21 with LysoTracker or MitoTracker was visualized live under Nikon EZ-C1 confocal microscopy, using $40 \mathrm{x} / 1.4$ plan Apo $\lambda$ s lens. All images were captured and processed using the NIS-Elements software (Nikon) and the ImageJ software (version $1.49 \mathrm{q}$ ). Fluorescence intensity profiles for the calculation of the Pearson colocalization co-efficient $\left(R^{2}\right)$ was generated in Image J using the plot profile function.

\section{Neutron Reflectometry}

Neutron reflection measurements were carried out on the CRISP reflectometer at ISIS Neutron and Muon source, UK [25, 26]. Three incident angles were used to cover a $Q$ range of $0.01-0.4$ $\AA^{-1}\left(0.33^{\circ}, 0.65^{\circ}\right.$, and $\left.1.45^{\circ}\right)$, and an instrument resolution $(\delta \lambda / \lambda$ of $3 \%)$ was fixed using collimating slits. Throughout the experiment, the temperature was maintained at $37^{\circ} \mathrm{C}$ by a circulating water bath.

Silicon blocks $(111,80 \times 50 \times 15 \mathrm{~mm}$; Sil'tronix, Archamps, France) were cleaned in mild piranha solution (5:4:1 mixture of $\mathrm{H}_{2} \mathrm{O}: \mathrm{H}_{2} \mathrm{SO}_{4}: \mathrm{H}_{2} \mathrm{O}_{2}$ ) for 10 min before rinsing, drying under $\mathrm{N}_{2}$, and UV ozone cleaning for a further $10 \mathrm{~min}$. The cleaned block was immediately installed in custom-made solid/liquid neutron reflectivity cells. The surface of the silicon was characterized in 2 contrasts $\left(\mathrm{H}_{2} \mathrm{O}\right.$ and $\left.\mathrm{D}_{2} \mathrm{O}\right)$ by in situ contrast exchange at $2 \mathrm{~mL} / \mathrm{min}$.

Supported lipid bilayers were formed by rehydration of a 90:10 mol\% lipid film consisting of tail deuterated 1,2-dimyristoyl-snglycero-3-phosphocholine (dDMPC; Avanti polar lipids, Alabaster, AL, USA) and 1,2-dimyristoyl-sn-glycero-3- phospho-L-serine (dDMPS). The lipid films were hydrated for $1 \mathrm{~h}$ at $40^{\circ} \mathrm{C}$ and tip sonicated $(50 \mathrm{~W}, 30 \mathrm{kHz}$ at $80 \%$ amplitude and $0.8 \mathrm{cycles} / \mathrm{s}, \mathrm{UP} 50 \mathrm{H}$, Hielscher, Teltow, Germany) to form small unilamellar vesicles for $15 \mathrm{~min}$ in $5 \mathrm{~min}$ intervals, with cooling, to ensure the mixture was not overheated. Immediately prior to injection into the reflectivity cells, $2 \mathrm{~mL}$ of the vesicle mixture $(0.2 \mathrm{mg} / \mathrm{mL})$ was diluted with 2 $\mathrm{mL}$ of $4 \mathrm{mM} \mathrm{CaCl}_{2}$ to form a $0.1 \mathrm{mg} / \mathrm{mL}$ lipid in $2 \mathrm{mM} \mathrm{CaCl}_{2}$ solution. The mixture was injected at $2 \mathrm{~mL} / \mathrm{min}$ and allowed to equilibrate for $20 \mathrm{~min}$ before being rinsed in water and $10 \mathrm{~mm}$ Tris buffer ( $\mathrm{pH} 7.4 ; 2 \mathrm{~mL} / \mathrm{min}, 20 \mathrm{~mL}$ ). The supported lipid bilayer was characterized in 3 Tris buffer contrasts prepared with $\mathrm{D}_{2} \mathrm{O}, \mathrm{H}_{2} \mathrm{O}$, and 38:62 v/v\% mixture that has the same scattering length density (SLD) as silicon (contrast-matched silicon). After characterization, $10 \mathrm{~mL}$ of each peptide ( $10 \mu \mathrm{M}$ in $10 \mathrm{mM}$ Tris buffer) was injected at $2 \mathrm{~mL} / \mathrm{min}$ and allowed to equilibrate for $30 \mathrm{~min}$ before being rinsed away, and the remaining bilayer was again characterized in 3 contrasts.

The data were modeled using RasCAL software (version 2014 Beta), and all bilayer datasets were fitted simultaneously [27]. Errors were calculated from the bootstrap error estimation in the software and used to calculate an overall value for the calculated values.

SLDs for the peptides were calculated from the Biomolecular SLD Calculator and found to be 2.98 and $3.07 \times 10^{-6} \AA^{-2}$ for HVF18 and GKY25, respectively [28]. The SLD of the peptides will shift depending on the H/D content of the subphase due to ex- 


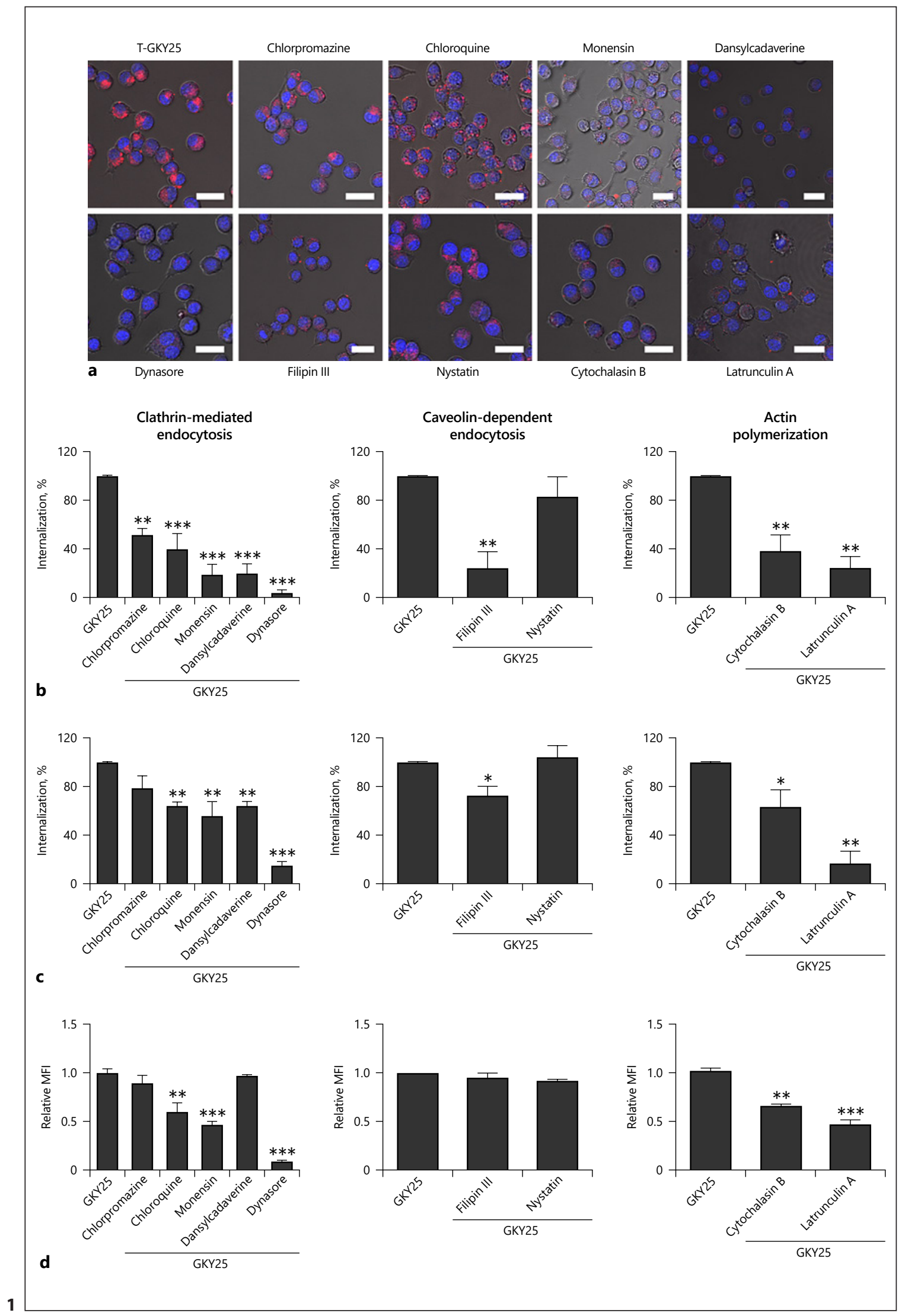

(For legend see next page.) 
changeable protons. For the peptide content calculations, the value was calculated based on a subphase containing $100 \% \mathrm{D}_{2} \mathrm{O} .100 \%$ $\mathrm{D}_{2} \mathrm{O}$ has previously been shown to be the most sensitive to hydrogenous material insertion to deuterated bilayers, whereas the $100 \%$ $\mathrm{H}_{2} \mathrm{O}$ contrast shows mainly the amount of lipid removed [29].

\section{Statistical Analysis}

Values are shown as means \pm SEM of " $n$ " independent experiments. Evaluation of the differences between control and test samples was done in GraphPad Prism version 7.0 using a one-way ANOVA with a Dunnett's or Tukey's multiple comparison test (when comparing more than 2 groups) or a paired $t$ test (when comparing 2 groups). A $p$ value of $<0.05$ was considered significant.

\section{Results}

\section{Clathrin-Dependent and -Independent Endocytosis}

Pathways Are Involved in GKY25 Internalization by

RAW264.7 Cells

Previously, we observed the presence of GKY25 in endosomes of RAW264.7 macrophages [11], which suggests that the internalization of this peptide is endocytosis-dependent. To clarify this uptake mechanism, RAW264.7 macrophages were treated with specific inhibitors for

Fig. 1. Clathrin-dependent and clathrin-independent endocytosis pathways are involved in T-GKY25 internalization by RAW264.7 cells. RAW264.7 cells were incubated for $30 \mathrm{~min}$ with the CME inhibitors chlorpromazine $(10 \mu \mathrm{M})$, chloroquine $(100 \mu \mathrm{M})$, monensin $(50 \mu \mathrm{M})$, dansylcadaverine $(50 \mu \mathrm{M})$, and dynasore $(30 \mu \mathrm{M})$; caveolin-dependent inhibitors filipin III $(10 \mu \mathrm{M})$ and nystatin $(10 \mu \mathrm{g} / \mathrm{mL})$; and actin polymerization inhibitors cytochalasin B $(10 \mu \mathrm{M})$ and latrunculin $\mathrm{A}(1 \mu \mathrm{M})$, followed by the addition of $2 \mu \mathrm{M}$ T-GKY25. After $1 \mathrm{~h}$ at $37^{\circ} \mathrm{C}$ in $5 \% \mathrm{CO}_{2}$, the uptake of GKY 25 was measured using confocal microscopy. Representative images (scale bars, $20 \mu \mathrm{m}$ ) (a) and the relative average peptide uptake (b) in the presence of endocytosis inhibitors, as compared to GKY25 alone. Results are means \pm SEM of $n=3$ experiments for chlorpromazine, dansylcadaverine, filipin III, cytochalasin B, latrunculin A; $n=4$ for monensin, dynasore; $n=5$ for chloroquine, nystatin. c After incubation with the indicated inhibitors, cells were washed twice to remove unbound inhibitors, followed by $1 \mathrm{~h}$ incubation with T-GKY25 and subsequent confocal microscopy analysis. Results are means \pm SEM of $n=3$ experiments for all listed inhibitors, except for chlorpromazine and chloroquine $(n=4)$. d Using the same experimental setup as in (a), the uptake of T-GKY25 in RAW264.7 cells was measured with a flow cytometer. Results are means \pm SEM of $n=3$ experiments for chloroquine, dynasore, and cytochalasin B; and $n=4$ for chlorpromazine, monensin, dansylcadaverine, filipin III, nystatin, and latrunculin A. Values are significantly $\left({ }^{*} p<0.05,{ }^{* *} p<0.005\right.$ and $\left.{ }^{* * *} p<0.0005\right)$ different from the controls as analyzed using a one-way ANOVA with a Dunnett's multiple comparisons test. CME, clathrin-mediated endocytosis. clathrin-dependent and clathrin-independent endocytic pathways, and the internalization of TAMRA-labeled GKY25 (T-GKY25) was analyzed using confocal microscopy and flow cytometry. Figure 1a illustrates the internalization of T-GKY25 in RAW264.7 cells pre-incubated with inhibitors for CME (chlorpromazine, chloroquine, monensin dansylcadaverine, and dynasore), caveolin-dependent endocytosis (filipin III and nystatin), and actin polymerization (cytochalasin B and latrunculin A). The uptake of T-GKY25 was significantly reduced with all 5 CME inhibitors and both actin polymerization inhibitors (shown in Fig. 1b). Additionally, T-GKY25 internalization was also inhibited by the caveolin-dependent inhibitor filipin III, although nystatin did not have a significant effect. To exclude that reduced internalization was caused by extracellular interactions, T-GKY25 and inhibitors were incubated for $1 \mathrm{~h}$ in the absence of cells followed by microscopic examination. The results show that $\mathrm{T}$ GKY25 is forming aggregates in the presence of monensin, as well as smaller aggregates in the presence of filipin III, nystatin, and cytochalasin B (shown in online suppl. Fig. S1a; see www.karger.com/doi/10.1159/000520831 for all online suppl. material). To avoid altered uptake due to aggregate formation, cells were incubated for 30 min with the inhibitors, washed, and incubated afterward with T-GKY25. As shown in Figure 1c, besides chlorpromazine, T-GKY25 uptake remained significantly inhibited by the different inhibitors, although differences in the percentage of internalization can be observed.

Next, using the methods of Figure 1b, we investigated whether we would observe similar effects by flow cytometry. Surprisingly, the CME inhibitor dansylcadaverine did not show any effect and neither did the caveolin-dependent endocytosis inhibitor filipin III (shown in Fig. 1d). The reason for the discrepancies between flow cytometry and confocal microscopy could be that the flow cytometer cannot distinguish between internalized TCPs and extracellular TCP bound to the cell membrane, whereas in confocal microscopy, extracellular TCPs can be excluded (illustrated in online suppl. Fig. S1b). Of note, the used concentrations of the endocytic inhibitors did not influence the viability of the cells (shown in online suppl. Fig. S1c). Together, the above results indicate that GKY25 is internalized in RAW264.7 cells via both clathrin-dependent and clathrin-independent pathways.

\section{GKY25 Is Transported to Lysosomes}

As GKY25 is taken up by macrophages, we next investigated the peptide's intracellular localization. Using the nuclear stain DRAQ5, we did not observe colocalization 


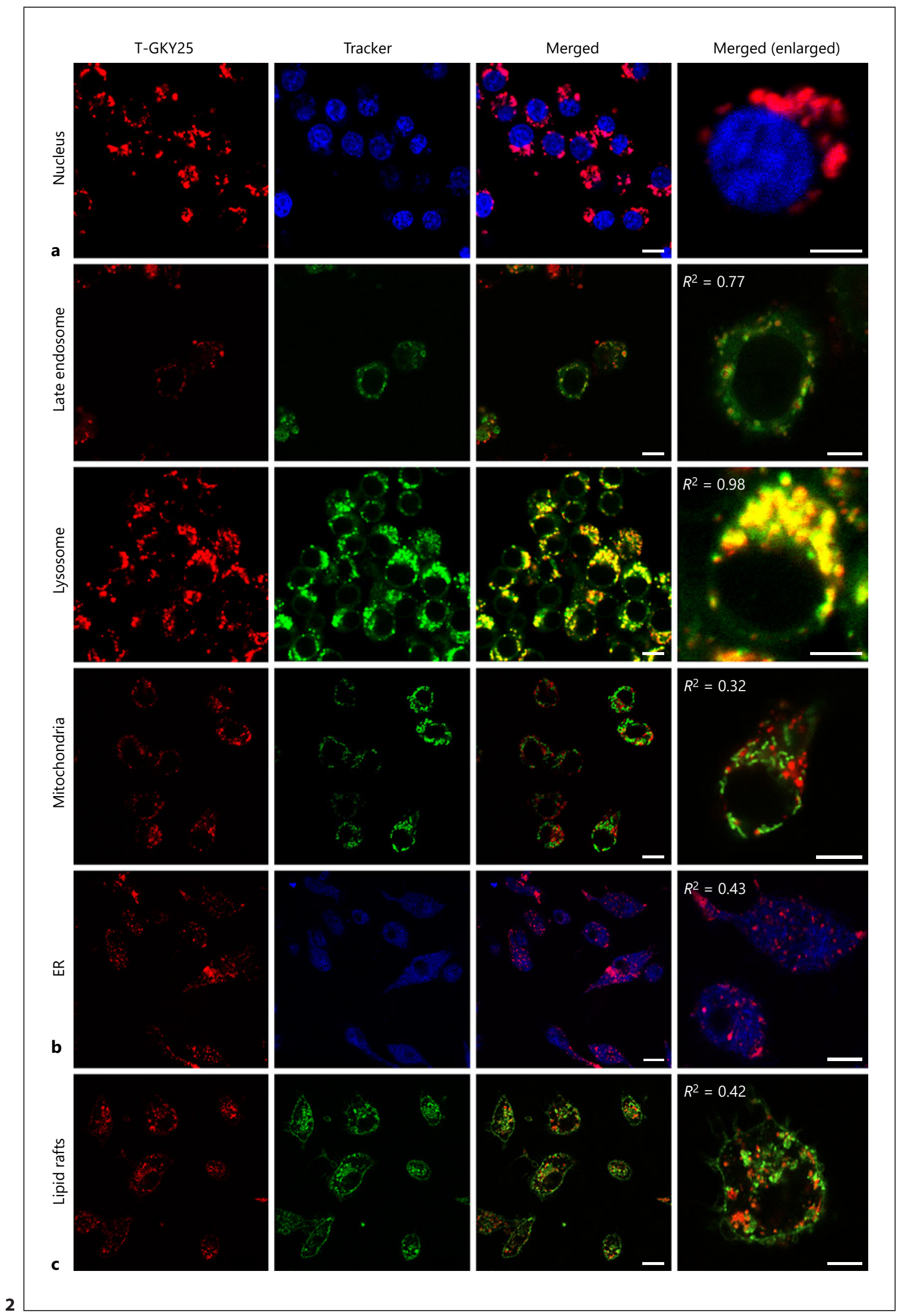

(For legend see next page.) 
of T-GKY25 with the cell nuclei, indicating that the peptide remained in the cytoplasm (shown in Fig. 2a). The nonhomogenous intracellular distribution of T-GKY25 suggested localization of the peptide in one or more cellular compartments. Indeed, we found a strong positive colocalization of T-GKY25 with late endosomes and lysosomes (shown in Fig. 2b), whereas only a weak correlation was observed with the mitochondria, endoplasmatic reticulum, and lipid-rafts (shown in Fig. 2b, c), indicating that the peptide does not co-localize with these cellular compartments. Taken together, after internalization, TGKY25 is delivered via endosomes to lysosomes.

\section{The Intracellular Stability of GKY25 Is \\ Time-Dependent}

As lysosomes are known for degrading a large variety of biological substances, we next investigated the stability of GKY25 after internalization in RAW264.7 cells. For this purpose, cells were incubated for up to $72 \mathrm{~h}$ with $6 \mu \mathrm{M}$ GKY25, washed, and lysed, and cell lysates were subjected to SDS-PAGE followed by Western blotting. The results showed that GKY 25 was detectable for the duration of the experiment, although the signal intensity decreased after $10 \mathrm{~h}$ (shown in Fig. 3a). However, as the continuous presence of extracellular peptide could interfere with the results, we next used a different experimental setup, where RAW264.7 cells were incubated for $1 \mathrm{~h}$ with GKY25, then washed to remove unbound peptide, and further incubated for up to $72 \mathrm{~h}$ in total. As shown in Figure 3b, internalized GKY25 was detectable for up to $10 \mathrm{~h}$ although the intensity of the peptide band decreased already after $2 \mathrm{~h}$.

Clathrin-Dependent and-Independent Pathways Are Involved in GKY25 Uptake during Stimulation with

LPS and Bacteria

As we previously showed that GKY25 binds to both LPS and bacteria $[11,12]$, we next investigated whether this binding would affect GKY25 internalization. For this

Fig. 2. T-GKY25 is transported to lysosomes. RAW264.7 cells were incubated with $2 \mu \mathrm{M}$ T-GKY25 (red) for $1 \mathrm{~h}$ at $37^{\circ} \mathrm{C}$ in $5 \% \mathrm{CO}_{2}$. Localization of T-GKY25 was investigated using the nuclear stain DRAQ5 (blue) (a), organelle trackers staining late endosomes, lysosomes, the mitochondria (all green), and endoplasmic reticulum (blue) (b), or the lipid raft staining cholera toxin subunit B (green) (c). Cells were stained for $30 \mathrm{~min}$, washed twice with DMEM, and images were taken using confocal microscopy. $R^{2}=$ Pearson coefficient for colocalization. One representative image out of 3 independent experiments is shown (scale bars, $10 \mu \mathrm{m}$ (merged images), $5 \mu \mathrm{m}$ (enlarged merged images)). purpose, RAW264.7 cells were treated with the indicated inhibitors for $30 \mathrm{~min}$ followed by the incubation with TGKY25 pre-incubated with E. coli BioParticles or E. coli LPS for $1 \mathrm{~h}$ (shown in Fig. 4). Confocal microscopy analysis showed that the presence of E. coli BioParticles or LPS did not substantially affect T-GKY25 internalization via $\mathrm{CME} /$ dynamin-dependent endocytosis and actin polymerization, as the inhibitors dynasore and cytochalasin $\mathrm{B}$ significantly decreased the peptide uptake similarly to TGKY25 alone. By contrast, filipin III was less effective in inhibiting peptide internalization in the presence of $E$. coli BioParticles than peptide alone, whereas the presence of LPS abrogated its inhibitory effects. This indicates that caveolin-dependent pathways may only play a minor role in the internalization of GKY25 during infection, when LPS and bacteria are present.

\section{Differential Uptake of TCPs in RAW264.7 Cells and THP-1 Cells}

As the TCPs FYT21 and HVF18 exert similar immunomodulatory effects as GKY25 on monocytes and macrophages, we investigated whether these peptides were also similarly internalized via clathrin-dependent and clathrin-independent pathways by RAW264.7 macrophages and THP-1 cells. Using flow cytometry, we found that the uptake of T-GKY25, T-FYT21, and T-HVF18 in RAW264.7 macrophages was significantly decreased by the dynamin inhibitor dynasore (shown in Fig. 5a), although the degree of inhibition was less for T-HVF18. Furthermore, cytochalasin B significantly suppressed TFYT21 and T-GKY25, but not T-HVF18, whereas the caveolin-dependent endocytosis inhibitor filipin III did not affect the internalization of any of the TCPs in RAW264.7 cells using this method (shown in Fig. 1d, 5a). The presence of LPS did not alter T-HVF18 uptake in RAW264.7 cells, whereas for T-GKY25 and T-FYT21, inhibition by cytochalasin B was no longer significant, while inhibition by filipin III became significant (shown in Fig. 5b). Surprisingly, these results for T-GKY25 + LPS are opposite to those obtained with confocal microscopy (shown in Fig. 4), showing again a discrepancy between the 2 methods. Of note, the measured median fluorescence intensity values of the samples are shown in online supplementary Table S1. As seen for GKY25 (shown in Fig. 2), after internalization, both HVF18 and FYT21 show a strong positive co-localization with lysosomes (shown in online suppl. Fig. S2a) and only a weak colocalization with mitochondria (shown in online suppl. Fig. S2b), indicating that all 3 peptides end up in the lysosomes. 
Next, we studied the uptake of TCPs using the human monocytic cell line THP-1. The internalization of T-GKY25 and T-FYT21 was significantly decreased only with dynasore, both in the absence and presence of LPS (shown in Fig. 5c, d). The internalization of THVF18 was not decreased by any of the inhibitors in the absence of LPS (shown in Fig. 5c), whereas in the pres- ence of LPS, it was significantly promoted in the presence of the inhibitor dynasore. Finally, cytochalasin B and filipin III did not significantly influence the uptake of the peptides by THP-1 cells in any condition. Notably, the used concentrations of the endocytic inhibitors did not influence the viability of the cells (shown in online suppl. Fig. S1c, d).

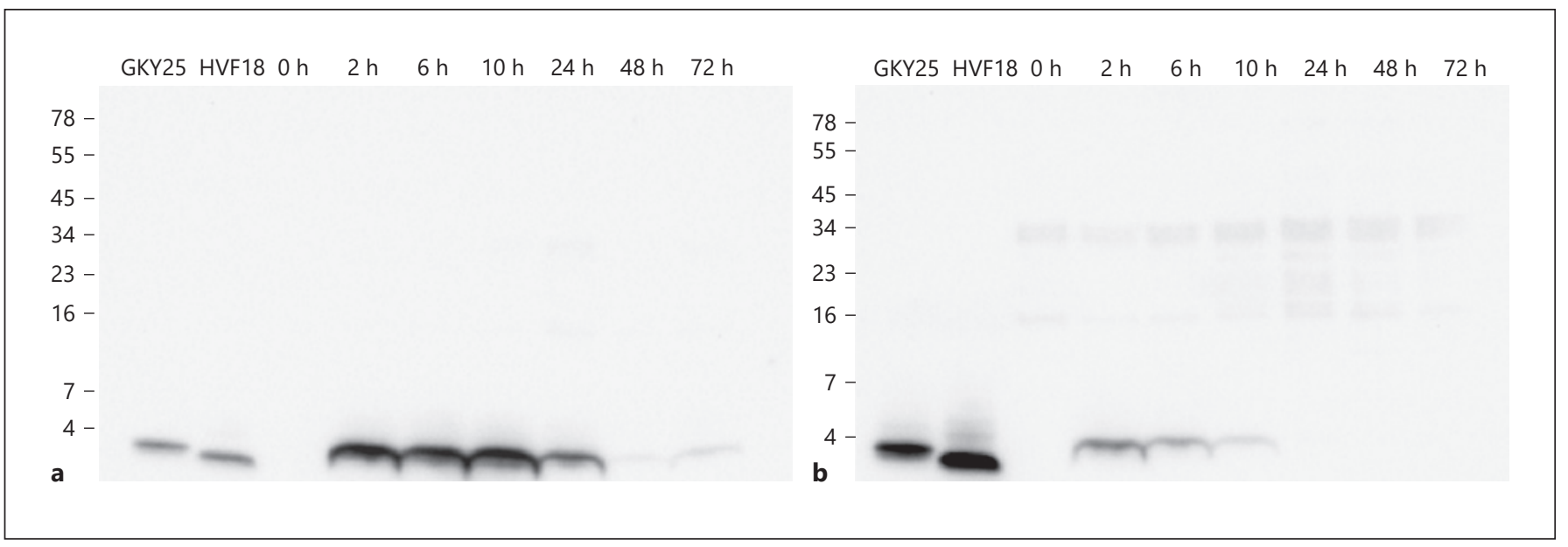

Fig. 3. Stability of internalized GKY25 in RAW264.7 cells. RAW264.7 cells were incubated with $6 \mu \mathrm{M}$ GKY25 for up to $72 \mathrm{~h}$ (a) or for $1 \mathrm{~h} \mathrm{(b)} \mathrm{followed} \mathrm{by} 2$ washes with PBS and further incubation up to $72 \mathrm{~h}$. After incubation, cells were washed and lysed, and GKY25 was detected in the lysate using Western blot analysis. GKY25 and HVF18 (1 nmol) were included as controls. One representative experiment out of 3 independent experiments is shown.
Fig. 4. Clathrin-dependent and clathrinindependent pathways are involved in TGKY25 internalization during stimulation with bacteria and LPS. RAW264.7 cells were incubated with dynasore $(30 \mu \mathrm{M})$, filipin III $(10 \mu \mathrm{M})$, and cytochalasin B $(10 \mu \mathrm{M})$ for $30 \mathrm{~min}$ at $37^{\circ} \mathrm{C}$. Subsequently, T-GKY25, pre-incubated with E. coli LPS or E. coli BioParticles for $1 \mathrm{~h}$ in $37^{\circ} \mathrm{C}$, was added to the RAW264.7 cells, and the uptake was measured using confocal microscopy. Results are means \pm SEM of $n=3$ experiments. Values are significantly $\left({ }^{*} p<\right.$ 0.05 and $* * * p<0.0005)$ different from the controls as analyzed using a one-way ANOVA with Dunnett's multiple comparison test. LPS, lipopolysaccharides.

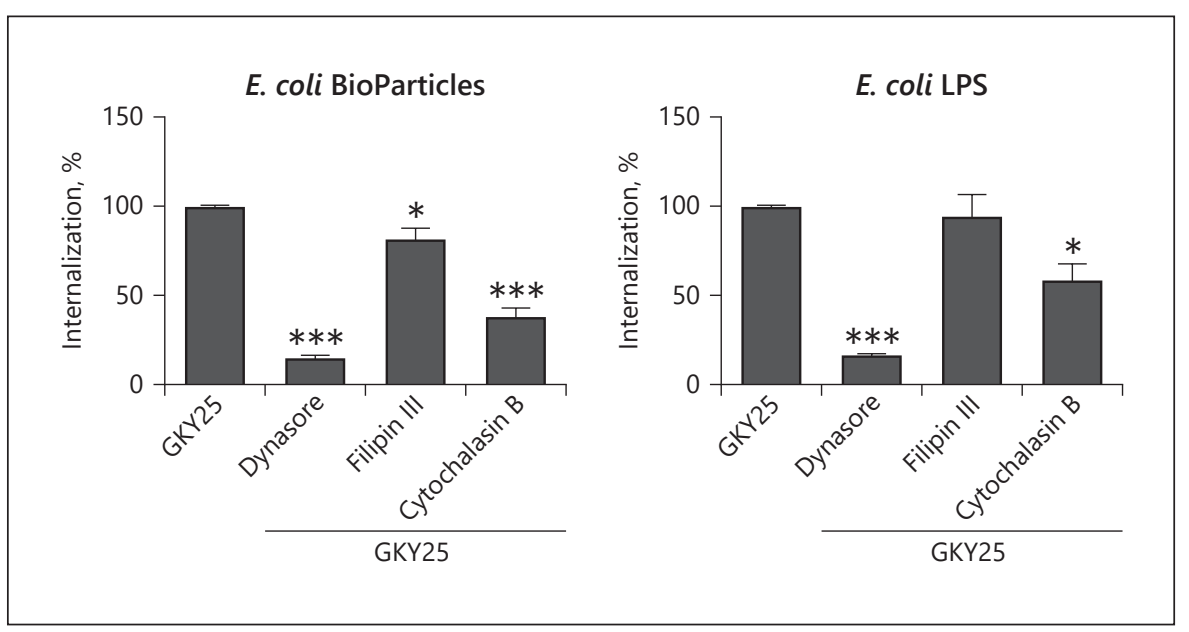

Fig. 5. TCPs are internalized differentially into RAW264.7 and THP- 1 cells. RAW264.7 cells $(\mathbf{a}, \mathbf{b})$ or THP- 1 cells $(\mathbf{c}, \mathbf{d})$ were treated with dynasore $(30 \mu \mathrm{M})$, filipin III $(10 \mu \mathrm{M})$, or cytochalasin B $(10 \mu \mathrm{M})$ for $30 \mathrm{~min}$ at $37^{\circ} \mathrm{C}$, followed by a $1 \mathrm{~h}$ incubation with $2 \mu \mathrm{M}$ of the indicated TCPs $(\mathbf{a}, \mathbf{c})$ or with the indicated TCPs pre-incubated with E.coli LPS $(10 \mathrm{ng} / \mathrm{mL})$ for $1 \mathrm{~h}$ at $37^{\circ} \mathrm{C}(\mathbf{b}, \mathbf{d})$. Results are means \pm SEM of $n=3-5$ (a), $n=3-6$ (b), $n=4-7$ (c), and $n=4-5$ (d) experiments. Values are significantly $\left({ }^{*} p<0.05,{ }^{* *} p<0.005\right.$, and $\left.{ }^{* * *} p<0.0005\right)$ different from the controls as analyzed using a one-way ANOVA with Dunnett's multiple comparison test. LPS, lipopolysaccharides; TCPs, thrombin-derived C-terminal peptides.
(For figure see next page.) 

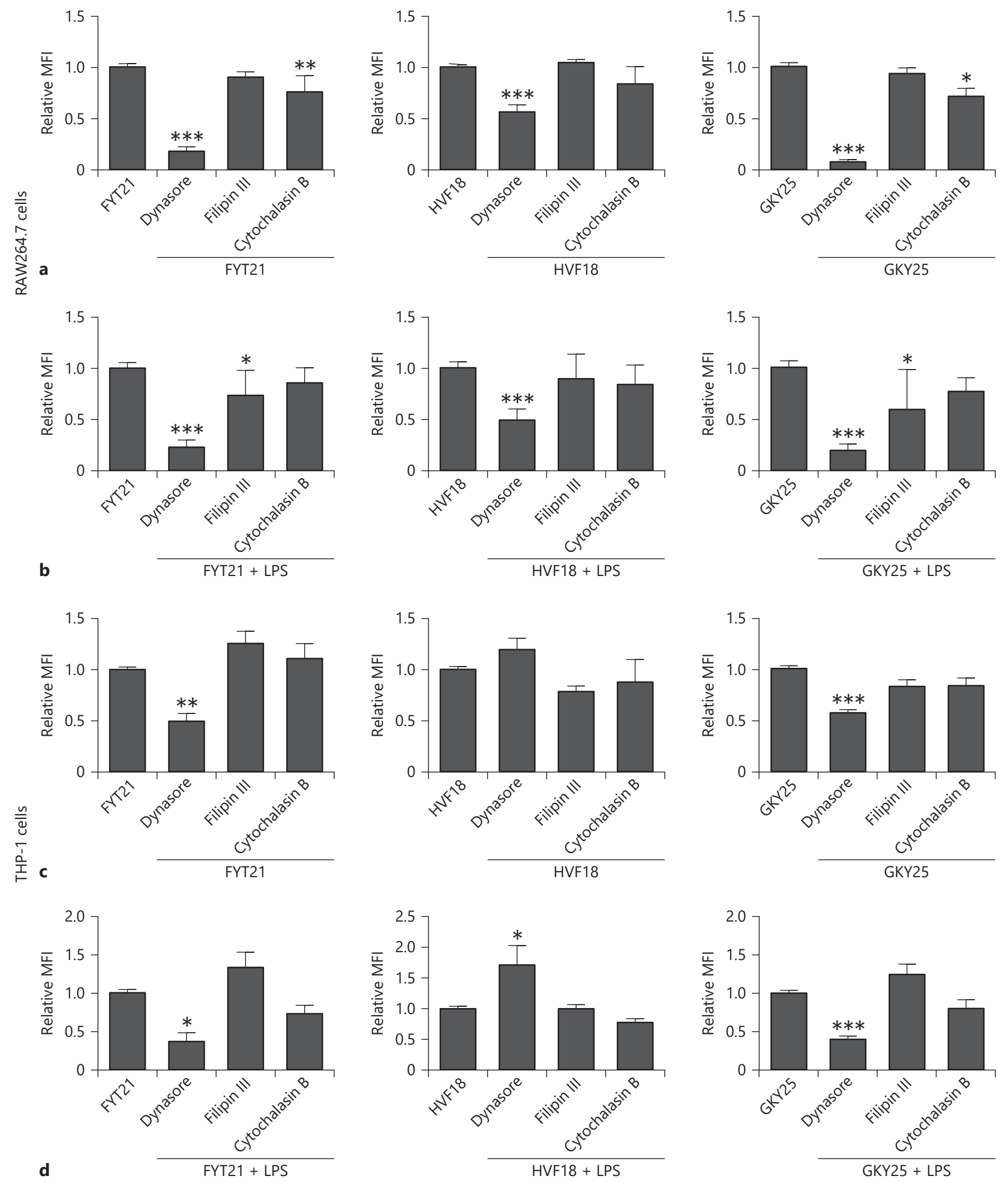


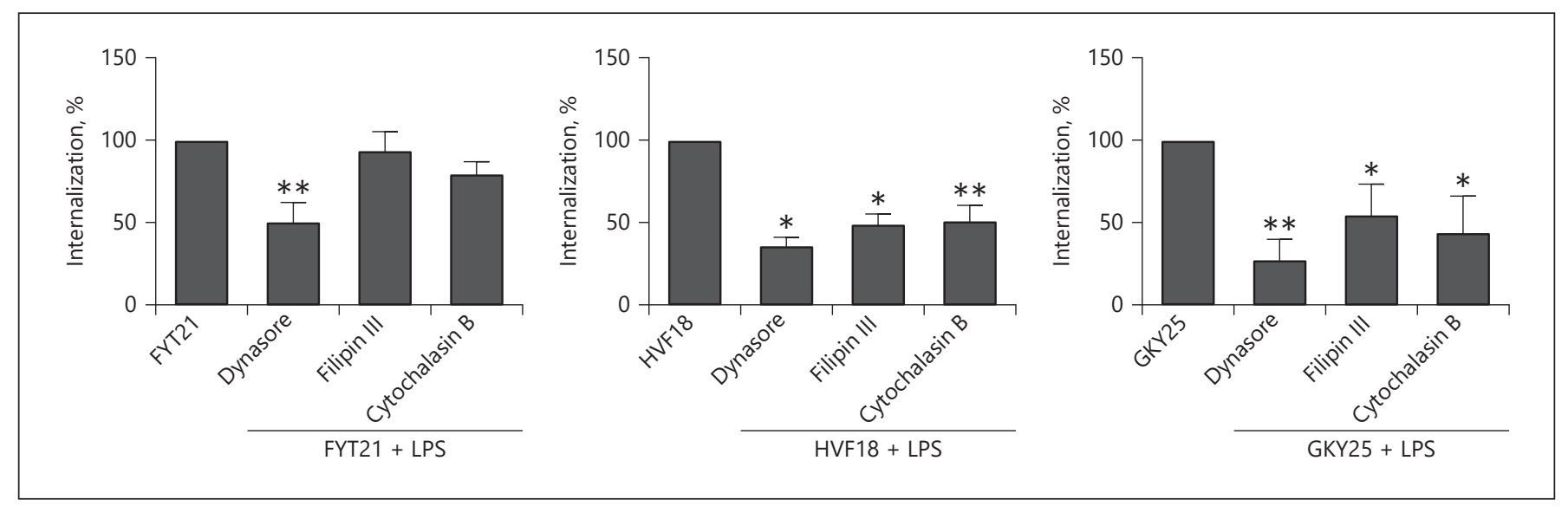

Fig. 6. Internalization of TCPs into primary monocyte-derived macrophages. CD14+ human monocytes were isolated from blood and stimulated for 7 days with GM-CSF ( $5 \mathrm{ng} / \mathrm{mL})$. Differentiated M1 macrophages were treated with dynasore $(30 \mu \mathrm{M})$, filipin III $(10 \mu \mathrm{M})$, or cytochalasin $\mathrm{B}(10 \mu \mathrm{M})$ for $30 \mathrm{~min}$ at $37^{\circ} \mathrm{C}$, followed by a $1 \mathrm{~h}$ incubation with $2 \mu \mathrm{M}$ T-GKY25, T-FYT21, or T-HVF18, pre- incubated with E. coli LPS ( $10 \mathrm{ng} / \mathrm{mL})$ for $1 \mathrm{~h}$ at $37^{\circ} \mathrm{C}$. Results are means \pm SEM of $n=3$ experiments. Values are significantly $\left({ }^{*} p<\right.$ 0.05 and $\left.{ }^{* *} p<0.005\right)$ different from the controls as analyzed using a one-way ANOVA with Dunnett's multiple comparison test. TCPs, thrombin-derived C-terminal peptides; LPS, lipopolysaccharides.

\section{Internalization of TCPs into Human Monocyte- Derived Macrophages}

As we observed differences in TCP uptake between murine RAW264.7 macrophages and human THP-1 monocytes, we next investigated whether this was due to cell type, species origin, or some third reason. For this purpose, we isolated CD14+ monocytes and differentiated them into pro-inflammatory macrophages. To make it physiologically relevant from an infection perspective, we added LPS.

The results showed that similar to THP-1 cells, only dynasore significantly inhibited the internalization of FYT21 (shown in Fig. 6). Surprisingly, all inhibitors decreased the uptake of both HVF18 and GKY25, which we did not see with RAW264.7 or THP-1 cells. Taken together, these results show that the pathways responsible for the internalization of TCPs are dependent on the type of peptide and the specific type of cell studied, whereas species origin of the cells or general cell type (monocytes vs. macrophages) do not seem to be determining factors.

\section{Differential Pore Formation and Peptide Insertion in \\ Lipid Bilayers}

Previously, we found peptide binding to a large variety of cells from human and murine origin as well as prokaryotes $[7,11,12]$, which suggests that direct interactions of the peptides with the lipid bilayer of the membranes are mainly responsible for cell binding. As FYT21 and GKY25 exert similar immunomodulatory and cytotoxic effects on monocytes and macrophages, which are more potent than the effects of HVF18, we compared membrane interactions of these 2 latter TCPs using neutron reflection on supported human cell membrane-mimicking lipid bilayers.

Neutron reflectivity data were modeled by simultaneously fitting the bare silicon surface and the supported lipid bilayer to constrain as many fitting parameters as possible. The supported lipid bilayer was modeled as a four-slab layer consisting of trapped water, hydrophilic head groups, hydrophobic tail region, and hydrophilic head groups. The model was further constrained by fixing the bilayer to be symmetrical (i.e., head group regions were modeled using the same values), and the area per molecule was fixed within error between the head and the tail region. For both samples, good fits were obtained for the supported lipid bilayer before the introduction of the peptide. There was no detectable water in the hydrophobic tail region, suggesting that the lipid bilayer was complete and defect-free. The calculated area per molecule for the lipid bilayer was found to be $59 \pm 1 \AA^{2}$, which is in good agreement with the literature [30].

Upon incubation with the peptides for $30 \mathrm{~min}$, the reflectivity of the bilayer in Tris/ $\mathrm{H}_{2} \mathrm{O}$ buffer decreased more for GKY25 than for HVF18 (shown in Fig. 7a, left panel), indicating more deuterated lipid removal from the bilayer by the former peptide. Furthermore, in Tris/ $\mathrm{D}_{2} \mathrm{O}$ buffer (shown in Fig. 7a, right panel), a minimum in the reflectivity is seen for GKY25 at $\sim 0.075 \AA^{-1}$, indicating 

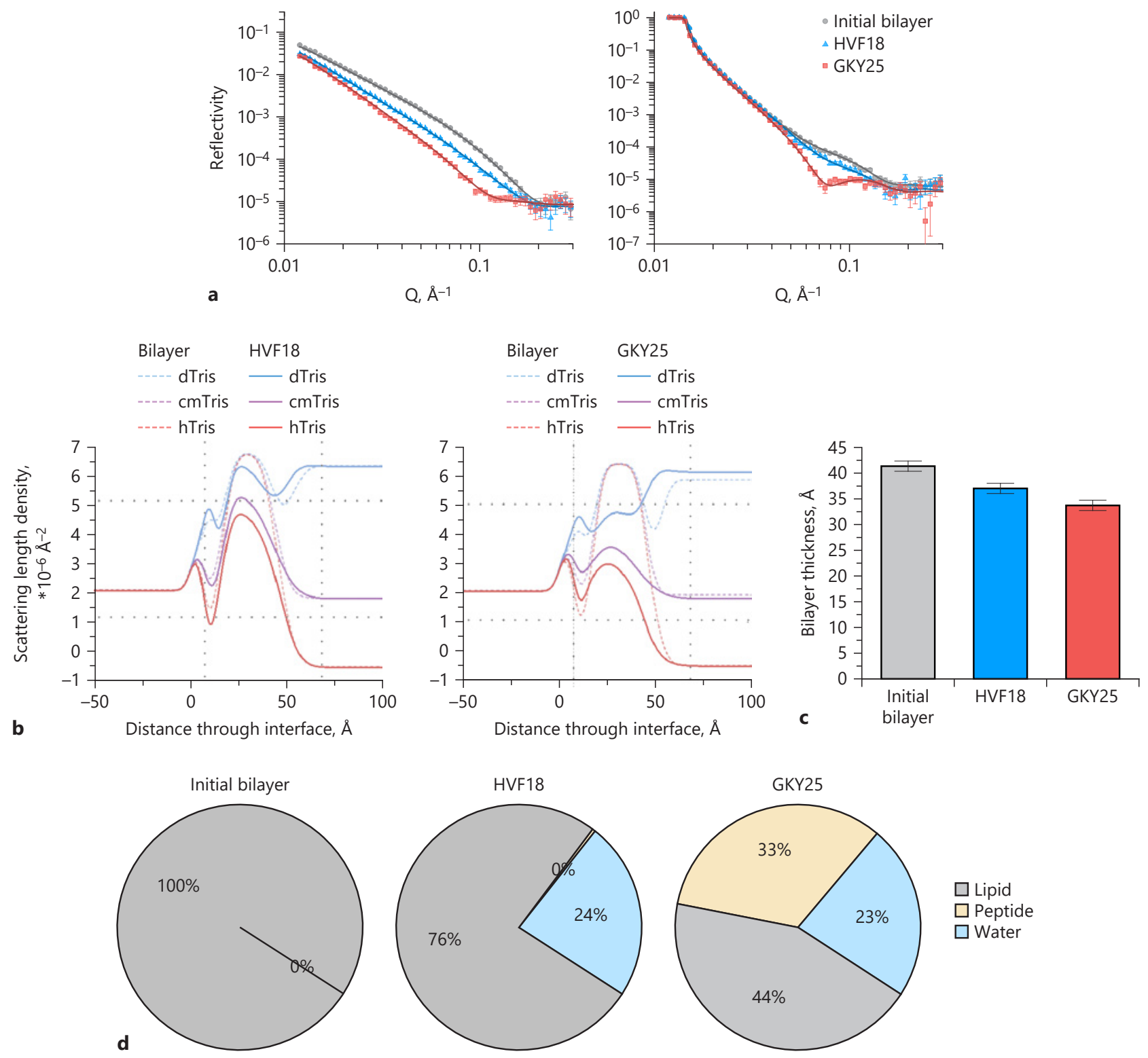

Fig. 7. TCP interactions with lipid bilayers. Supported lipid bilayers with a 90:10 mol\% dDMPC:dDMPS composition were generated and incubated with $10 \mu \mathrm{M}$ HVF18 or $10 \mu \mathrm{M}$ GKY25. a Measured (markers) and modeled (lines) neutron reflectivity data of supported lipid bilayers before (gray circles) and after incubation with either HVF18 (blue triangles) or GKY25 (red squares). Left shows data obtained in hydrogenous buffer, and right shows deuterated buffer. b SLD profiles of GKY25 and HVF18. Supported lipid bilayers with a 90:10 mol\% dDMPC:dDMPS composition were generated and incubated with $10 \mu \mathrm{M}$ HVF1 18 or $10 \mu \mathrm{M}$ GKY 25 .
SLD profiles were calculated from data fits of the bilayer before (dashed lines) and after (solid lines) incubation with either HVF18 (left) or GKY25 (right). c Modeled bilayer thickness, before (gray) and after incubation with HVF18 (blue) or GKY25 (red). d Modeled volume fractions of the hydrophobic tail region of the supported lipid bilayer after incubation with HVF18 or GKY25. Removal of lipid in the tail region was mirrored in head group removal in all cases. SLD, scattering length density; TCP, thrombin-derived C-terminal peptide. 
the insertion of the hydrogenous material, as previously described for lipid exchange with lipoproteins [29]. The fitted models are shown in Figure $7 \mathrm{a}$ as lines and in Figure $7 \mathrm{~b}$ as the SLD profiles through the silicon and supported lipid bilayer. Model fits to the data show the amount of the lipid removed from the bilayer was $24 \pm 1 \%$ for HVF1 8 and $56 \pm 2 \%$ for GKY25. Together with lipid removal, the head to head distance of the bilayer was found to thin after peptide incubation, from $41 \pm 1 \AA$ to $37 \pm 1 \AA$ for HVF18, and $34 \pm 1 \AA$ for GKY25 (shown in Fig. 7c). GKY25 insertion into the hydrophobic tail region of the bilayer was calculated to be $33 \pm 3 \%$, whereas for HVF18, the amount of peptide insertion was found to be negligible $(0 \pm 2 \%)$. The remainder of the layer was modeled as water, indicating pore formation covering just below onequarter of the bilayer surface for both peptides studied (shown in Fig. 7d). The SLDs used for the fittings are given in online supplementary Table S2a, and the bilayer parameters obtained from fits are provided in online supplementary Table S2b. Notably, it was not possible to fit the data to include an adsorbed layer of peptide on top of the lipid surface or lying within the hydrophilic head group regions as seen previously for LL-37 [31, 32].

\section{Discussion}

TCPs are released in wounds by proteolytic cleavage of thrombin and exert multiple biological functions in response to bacteria and pathogen-associated molecular patterns such as LPS, involving the modulation of proinflammatory responses $[5,6,11,12]$. As demonstrated in a previous work, the TCPs FYT21, GKY25, and HVF18 are bound to and internalized by THP-1 monocytes and RAW264.7 macrophages $[7,11,12]$. However, TCP binding is not limited to these cells, as we showed binding of native TCPs to neutrophils in fibrin slough, as well as binding of FYT21 to neutrophils, lymphocytes, and platelets in both human and murine blood $[6,7]$, suggesting that TCPs bind to a common cell membrane structure. Moreover, the finding that TCP binding is temperaturedependent indicates that membrane fluidity is important for cell binding and suggests a role for endocytosis pathways. In the present study, we set out to further elucidate the uptake mechanisms of TCPs in monocytes and macrophages. Using a range of inhibitors of CME, caveolindependent endocytosis, and actin polymerization, we conclude that TCPs are differentially internalized depending on the length and composition of the peptides, bacterial presence, as well as the cell type studied.

Uptake of TCPs by Monocytes and Macrophages
In our initial experiments, GKY25 uptake was investigated, and we found that all 3 processes are involved in the internalization of GKY25 into unstimulated RAW264.7 cells. As GKY25 binds to both LPS and bacteria, we investigated whether this binding would change the above results, and found that caveolin-dependent endocytosis pathways may only play a minor role in peptide uptake during bacterial infections. In agreement, colocalization experiments showed that GKY25 was only weakly correlating with lipid rafts, and as caveolae are a subset of lipid rafts [33], these results further indicate that CME, and not caveolin-dependent uptake, is responsible for the internalization of GKY25 in RAW264.7 cells during infection. Previous electron microscopy results showed the uptake of GKY25 together with Tolllike receptor 4 and LPS in endosomes of RAW264.7 macrophages [11]. However, as dynamin- and clathrin-dependent pathways mediate the endocytosis of LPS receptor complexes into endosomes and subsequently lysosomes [34], it was unclear whether the peptides were just hitchhiking. We now show that all 3 peptides are transported to the lysosomes, via the late endosomes, also in the absence of other cell stimuli that would trigger receptor-mediated internalization. Notably, it has been reported that HDP LL-37 is also primarily endocytosed by clathrin-dependent pathways in macrophages, and is then translocated to endosomes and lysosomes, but also the Golgi apparatus [13], which we did not observe for the TCPs.

Although TCPs inhibit the activation of RAW264.7 macrophages by LPS similar to that of THP-1 monocytes $[6,11,12]$, we found that the pathways of peptide internalization are cell- and peptide-dependent. Although we do not know the reason for this, we can exclude that it is due to differences in species origin (mouse vs. human) or cell differentiation (monocytes vs. macrophages). Surprisingly, in THP-1 cells, HVF18 showed increased peptide signals in the presence of the dynamin inhibitor. As increased peptide internalization is unlikely, these results are probably caused by peptide accumulation on the membrane of these cells. In this respect, it should be noted that the results are to some extent dependent on the method of analysis. Flow cytometry cannot distinguish between internalized TCPs and extracellular TCPs bound on the cell membrane, whereas in confocal microscopy, extracellular peptides can be excluded. In agreement, differences in results were observed for the uptake in RAW264.7 macrophages depending on the method of analysis used. However, as THP-1 cells are nonadherent cells, confocal microscopy did not give proper results,

J Innate Immun 2022;14:418-432 DOI: $10.1159 / 000520831$ 
and therefore, we used flow cytometry when comparing THP-1 with RAW264.7. Clearly, one should be cautious making hard conclusions with the results obtained with the latter method. Also, it should be kept in mind that the used inhibitors are not equally potent or specific. As an example, the dynamin inhibitor dynasore is often used for studying the inhibition of CME. However, dynamin is also involved in the internalization of caveolae [35] and phagosomes [36]. Moreover, dynasore has been shown to exert dynamin-independent effects, including disruption of lipid rafts, inhibition of membrane ruffling, and destabilization of F-actin [37]. Nevertheless, as we used a range of inhibitors, we can conclude that dynamin-mediated endocytosis and CME play an important role in TCP internalization.

From a structural perspective, it is interesting that the uptake of endogenously formed HVF18 in RAW264.7 was only significantly reduced in the presence of the CME inhibitor dynasore, whereas uptake of the 3 amino acids longer, but similarly charged FYT21, released from thrombin by bacteria is comparable to the even longer prototypic GKY25, which also has a higher positive charge. Furthermore, dynamin inhibition was approximately $50 \%$ for HFV 18 , whereas it was over $80 \%$ for the other 2 peptides. The internalization of GKY25 and FYT21 in THP-1 cells was also similarly affected by the inhibitors, whereas clear differences were observed in monocyte-derived M1 macrophages. These results suggest that the internalization of TCPs may depend on multiple factors involving peptide length and composition of the peptides, but not charge. Indeed, there is a prominent difference regarding the contribution of the aromatic amino acids tyrosine and phenylalanine to hydrophobicity in GKY25 and FYT 21 as compared to HVF18. These sequence-specific factors clearly need to be determined further in future experiments, utilizing specific peptide variants. We previously showed that a scrambled version of GKY25, namely WFF25 (WFFFYYLIIGGGVVTHQQRKKKKDE), did not show any immunomodulatory effects and was not taken up by RAW cells [11], indeed indicating that peptide primary sequence and secondary structure are essential.

As TCPs are shown to bind a large variety of both eukaryotic and prokaryotic cells [7, 11, 12], which suggests nonreceptor-mediated, direct interactions of the peptides with lipid bilayers, we investigated peptide-membrane interactions using neutron reflectometry. We found that the presence of GKY25 resulted in more than twice the reduction in lipid content, as compared to HVF18, and as a consequence, bilayer thickness was also reduced more for the former peptide. These results suggest that the larger TCPs lead to more membrane destabilization, which is in agreement with our previous reported data, showing that GKY25 and FYT21 induce hemolysis in $0.5 \%$ whole blood from $15 \mu \mathrm{M}$, whereas HVF18 did not induce lysis up to $80 \mu \mathrm{M}[5,7,11,12,38]$. Interestingly, the reduction in lipids was not the result of differences in pore formation, as this was similar for both peptides. Instead, the presence of GKY25, but not HFV18, resulted in significant peptide incorporation into the membrane. Although this model is simplistic, as interactions with other membrane components than the lipid bilayer are excluded, the results are in agreement with our flow cytometry data for cells without LPS, as we observed much lower median fluorescence intensities with HVF18 than with GKY 25 or FYT21, indicating that less peptide was bound to and/or internalized into the cells. Together, these observations indicate that HVF18 has lower membrane-penetrating properties than GKY25 and FYT21, which may influence internalization pathways. Notably, HVF18 is also a far less potent inhibitor of inflammatory responses than the other 2 peptides $[7,11,12]$, although that is mostly due to direct interactions with the stimuli, independent of membrane binding.

From a biological perspective, monocytes and macrophages are phagocytic cells that play an important role in clearing of infections at the site of injury by the engulfment of invading pathogens and the release of pro-inflammatory cytokines [39]. The presence of HDPs like TCPs, released by endogenous and exogenous enzymes at the site of injury, prevents excessive pro-inflammation by binding to PAMPs and bacteria, which are subsequently internalized into phagocytes. For LL-37, it has been reported that colocalization of peptides with bacteria in macrophages leads to increased intracellular killing [13]. As we show that TCPs are detectable in macrophages for at least $10 \mathrm{~h}$, internalized TCPs may enhance bacterial killing in macrophages as well. Indeed, TCPs may switch their mode of action from mainly anti-inflammatory at neutral $\mathrm{pH}$ to antibacterial at acidic $\mathrm{pH}$ [40] due to differences in peptide oligomerization [41]. However, as pre-incubation of E. coli BioParticles with TCPs does not alter phagocytosis by human and murine macrophages, and neither does pre-incubation of macrophages with the peptides prior to adding bacteria [12], potential changes in intracellular killing due to the presence of peptides may not reflect the major physiological role of TCPs. Instead, TCP binding to LPS, bacteria, or E. coli BioParticles leads to the inhibition of pro-inflammatory responses to these agonists [12]. Taken together, 
the results presented here therefore provide further molecular clues to the actions of TCPs in vivo. Indeed, a complex picture is emerging where the different endocytosis pathways involved in the internalization of TCPs are dependent on the length and composition of the peptide, the specific type of cell, as well as the presence of bacterial stimuli. Interestingly, no association was found with species origin (mouse vs. human) and cell differentiation (monocytes vs. macrophages). Similar observations have been made for other peptides, such as cellpenetrating peptides [42]. Although we cannot exclude additional uptake mechanisms, such as specific receptor interactions, our results indicate that dynamin-dependent endocytosis is a major mechanism for the internalization of TCPs into mammalian cells.

From a clinical perspective, the modulatory properties of HDPs like TCPs could have therapeutic potential. Pathogen-associated molecular patterns such as LPS induce excessive inflammation as seen in bacterial sepsis, causing release of cytokines, acute phase proteins and reactive oxygen species, and over-activation of the coagulation and complement systems [43-45]. Whereas antibiotics do not address this systemic inflammation, TCPs have been shown to not only kill bacteria but also reduce cytokines and normalize coagulation activation in experimental models of endotoxin shock and bacterial sepsis [5, 6]. Furthermore, in porcine wound infection models, a TCP-25-containing hydrogel was shown to have a dual function, reducing both bacterial levels and local inflammation, thereby hastening healing [46]. As TCPs, like other HDPs, have attracted significant attention as alternatives to conventional antibiotics, owing to their ability to kill a broad spectrum of microbes and to modulate a variety of host inflammatory responses, understanding of both the extracellular modes of actions of these peptides, and the uptake mechanisms and intracellular fate, will give important clues to support the rational selection and development of these HDPs into next-generation therapeutics.

\section{Acknowledgements}

The authors would like to thank Ann-Charlotte Strömdahl and Ariane Neumann for their help with the primary monocyte isolation and culturing. Lukas Boge, Liv Sofia Elinor Damgaard, and Rob Barker are gratefully acknowledged for their help with neutron reflection experiments. Furthermore, we thank ISIS Neutron and Muon Spallation Source for providing access and experimental time (RB number: 1810031, DOI:10.5286/ISIS.E.92922658), and the Lund University Bioimaging Center (LBIC) for providing experimental resources.

Uptake of TCPs by Monocytes and

Macrophages

\section{Statement of Ethics}

This study was carried out in accordance with the recommendations of the Ethics Committee at Lund University, Lund, Sweden, with written informed consent from all subjects. The protocol for the use of human blood components (permit no. 2017:12) was approved by the Ethics Committee at Lund University.

\section{Conflict of Interest Statement}

Dr. Schmidtchen is a founder of in 2 cure AB, a company developing anti-inflammatory peptides of thrombin for therapeutic applications (patents US8735353B2, EP2480567B1, EP1987056B1, and US8076286B2). The other authors declare no competing financial interests.

\section{Funding Sources}

This work was supported by grants from Alfred Österlunds Foundation, Hudfonden (Edvard Welanders Stiftelse and Finsenstiftelsen), O.E. och Edla Johanssons Foundation, Thelma Zoégas Foundation, the Royal Physiographic Society, and Åke Wibergs foundation awarded to M.J.A.P., from Knut and Alice Wallenberg Foundation, the Swedish Strategic Research Foundation, the Swedish Research Council (2017-02341, 2020-02016) and the Swedish Government Funds for Clinical Research (ALF) to A.S., and from LEO Foundation to K.L.B.

\section{Author Contributions}

F.C.H., A.S., and M.J.A.P. conceived and designed the experiments. F.C.H. and A.N. performed the in vitro cell studies. K.L.B. and M.C. performed the neutron reflection experiments. F.C.H., A.N., and K.L.B. analyzed the data and prepared the figures. F.C.H. and M.J.A.P. wrote the article. All authors discussed the results and commented on the manuscript.

\section{Data Availability Statement}

All data generated or analyzed during this study are included in this article. Further inquiries can be directed to the corresponding author.

\section{References}

1 Wolberg AS, Campbell RA. Thrombin generation, fibrin clot formation and hemostasis. Transfus Apher Sci. 2008;38(1):15-23.

2 Licari LG, Kovacic JP. Thrombin physiology and pathophysiology. J Vet Emerg Crit Care. 2009;19(1):11-22.

3 Petrlova J, Hansen FC, van der Plas MJA, Huber RG, Morgelin M, Malmsten M, et al. Aggregation of thrombin-derived C-terminal fragments as a previously undisclosed host defense mechanism. Proc Natl Acad Sci U S A. 2017;114(21):E4213-22. 
4 Petrlova J, Petruk G, Huber RG, McBurnie EW, van der Plas MJA, Bond PJ, et al. Thrombin-derived C-terminal fragments aggregate and scavenge bacteria and their proinflammatory products. J Biol Chem. 2020;295(11): 3417-30.

5 Papareddy P, Rydengard V, Pasupuleti M, Walse B, Morgelin M, Chalupka A, et al. Proteolysis of human thrombin generates novel host defense peptides. PLoS Pathog. 2010; 6(4):e1000857.

6 Kalle M, Papareddy P, Kasetty G, Morgelin M, van der Plas MJ, Rydengard V, et al. Host defense peptides of thrombin modulate inflammation and coagulation in endotoxin-mediated shock and Pseudomonas aeruginosa sepsis. PLoS One. 2012;7(12):e51313.

7 van der Plas MJA, Bhongir RK, Kjellstrom S, Siller H, Kasetty G, Morgelin M, et al. Pseudomonas aeruginosa elastase cleaves a C-terminal peptide from human thrombin that inhibits host inflammatory responses. Nat Commun. 2016;7:11567.

8 Saravanan R, Adav SS, Choong YK, van der Plas MJA, Petrlova J, Kjellstrom S, et al. Proteolytic signatures define unique thrombinderived peptides present in human wound fluid in vivo. Sci Rep. 2017;7(1):13136.

9 Singh S, Kalle M, Papareddy P, Schmidtchen A, Malmsten M. Lipopolysaccharide interactions of C-terminal peptides from human thrombin. Biomacromolecules. 2013;14(5):1482-92.

10 Saravanan R, Holdbrook DA, Petrlova J, Singh S, Berglund NA, Choong YK, et al. Structural basis for endotoxin neutralization and anti-inflammatory activity of thrombinderived C-terminal peptide. Nat Commun. 2018;9:2762.

11 Hansen FC, Kalle-Brune M, van der Plas MJ, Stromdahl AC, Malmsten M, Morgelin M, et al. The Thrombin-derived host defense peptide GKY25 inhibits endotoxin-induced responses through interactions with lipopolysaccharide and macrophages/monocytes. I Immunol. 2015;194(11):5397-406.

12 Hansen FC, Strömdahl AC, Mörgelin M, Schmidtchen A, van der Plas MJA. Thrombin-derived host-defense peptides modulate monocyte/macrophage inflammatory responses to gram-negative bacteria. Front Immunol. 2017;8:843.

13 Tang X, Basavarajappa D, Haeggström JZ, Wan M. P2X7 receptor regulates internalization of antimicrobial peptide LL-37 by human macrophages that promotes intracellular pathogen clearance. J Immunol. 2015;195(3) 1191-201.

14 Kawaguchi Y, Takeuchi T, Kuwata K, Chiba J, Hatanaka Y, Nakase I, et al. Syndecan-4 is a receptor for clathrin-mediated endocytosis of arginine-rich cell-penetrating peptides. Bioconjugate Chem. 2016;27(4):1119-30.

15 Matsubara T, Otani R, Yamashita M, Maeno $\mathrm{H}$, Nodono $\mathrm{H}$, Sato T. Selective intracellular delivery of ganglioside GM3-binding peptide through caveolae/raft-mediated endocytosis. Biomacromolecules. 2017;18(2):355-62.
16 Schlegel R, Dickson RB, Willingham MC, Pastan IH. Amantadine and dansylcadaverine inhibit vesicular stomatitis virus uptake and receptor-mediated endocytosis of alpha 2-macroglobulin. Proc Natl Acad Sci U S A. 1982;79(7):2291-5.

17 Wang LH, Rothberg KG, Anderson RG. Misassembly of clathrin lattices on endosomes reveals a regulatory switch for coated pit formation. J Cell Biol. 1993;123:1107-17.

18 Dickson RB, Willingham MC, Pastan IH. Receptor-mediated endocytosis of alpha 2-macroglobulin: inhibition by ionophores and stimulation by $\mathrm{Na}+$ and $\mathrm{HCO} 3(-)$. Ann N Y Acad Sci. 1982;401:38-49.

19 Macia E, Ehrlich M, Massol R, Boucrot E, Brunner C, Kirchhausen T. Dynasore, a cellpermeable inhibitor of dynamin. Dev Cell. 2006;10:839-50.

20 Kitajima Y, Sekiya T, Nozawa Y. Freeze-fracture ultrastructural alterations induced by filipin, pimaricin, nystatin and amphotericin $B$ in the plasmia membranes of Epidermophyton, Saccharomyces and red complex-induced membrane lesions. Biochim Biophys Acta. 1976;455:452-65.

21 Rodal SK, Skretting G, Garred O, Vilhardt F, van Deurs B, Sandvig K. Extraction of cholesterol with methyl-beta-cyclodextrin perturbs formation of clathrin-coated endocytic vesicles. Mol Biol Cell. 1999;10:961-74.

22 Fujimoto LM, Roth R, Heuser JE, Schmid SL. Actin assembly plays a variable, but not obligatory role in receptor-mediated endocytosis in mammalian cells. Traffic. 2002;1(2):161-71.

23 Peterson JR, Mitchison TJ. Small molecules, big impact: a history of chemical inhibitors and the cytoskeleton. Chem Biol. 2002;9: 1275-85.

24 van der Plas MJA, van Dissel JT, Nibbering $\mathrm{PH}$. maggot secretions skew monocyte-macrophage differentiation away from a pro-inflammatory to a pro-angiogenic type. PLoS One. 2009;4(11):e8071.

25 Penfold J, Ward RC, Williams WG. A timeof-flight neutron reflectometer for surface and interfacial studies. J Phys E Sci Instrum. 1987;20(11):1411-7.

26 Nunez V, Boothroyd AT, Reynolds J, Penfold J, Langridge S, Bucknall DG, et al. Improvements to the Polarised-Neutron Reflectometry CRISP. Phys B Condens Matter. 1997; 241-243:148-50.

27 download R. SourceForge.net. Available from: https://sourceforge.net/projects/rscl/ Accessed 2020 Feb 20.

28 Calculator BSLD. Available from: http:// psldc.isis.rl.ac.uk/Psldc/ Accessed 2020 Jun 17.

29 Browning KL, Lind TK, Maric S, Malekkhaiat-Haffner S, Fredrikson GN, Bengtsson E, et al. Human lipoproteins at model cell membranes: effect of lipoprotein class on lipid exchange. Sci Rep. 2017;7(1):7478.

30 Nagle JF, Tristram-Nagle S. Structure of lipid bilayers. Biochim Biophys Acta. 2000;1469(3): 159-95.
31 Boge L, Browning KL, Nordstrom R, Campana M, Damgaard LSE, Seth Caous J, et al. Peptide-loaded cubosomes functioning as an antimicrobial unit against Escherichia coli. ACS Appl Mater Interfaces. 2019;11(24):2131422.

32 Nordstrom R, Browning KL, Parra-Ortiz E, Damgaard LSE, Haffner SM, Maestro A, et al. Membrane interactions of antimicrobial peptide-loaded microgels. J Colloid Interface Sci. 2020;562:322-32.

33 Parton RG, Richards AA. Lipid rafts and caveolae as portals for endocytosis: new insights and common mechanisms. Traffic. 2003; 4(11):724-38.

34 Husebye $\mathrm{H}$, Halaas $\mathrm{O}$, Stenmark $\mathrm{H}$, Tunheim G, Sandanger O, Bogen B, et al. Endocytic pathways regulate Toll-like receptor 4 signaling and link innate and adaptive immunity. EMBO J. 2006;25(4):683-92.

35 Henley JR, Krueger EW, Oswald BJ, McNiven MA. Dynamin-mediated internalization of caveolae. J Cell Biol. 1998;141(1):85-99.

36 Marie-Anais F, Mazzolini J, Herit F, Niedergang F. Dynamin-actin cross talk contributes to phagosome formation and closure. Traffic. 2016;17(5):487-99.

37 Preta G, Cronin JG, Sheldon IM. Dynasore: not just a dynamin inhibitor. Cell Commun Signal. 2015;13:24.

38 Kasetty G, Papareddy P, Kalle M, Rydengard V, Morgelin M, Albiger B, et al. Structure-activity studies and therapeutic potential of host defense peptides of human thrombin. Antimicrob Agents Chemother. 2011;55(6):288090.

39 Koh TJ, DiPietro LA. Inflammation and wound healing: the role of the macrophage. Expert Rev Mol Med. 2011;13:e23.

40 Holdbrook DA, Singh S, Choong YK, Petrlova J, Malmsten M, Bond PJ, et al. Influence of $\mathrm{pH}$ on the activity of thrombin-derived antimicrobial peptides. Biochim Biophys Acta Biomembr. 2018;1860(11):2374-84.

41 Petruk G, Petrlova J, Samsudin F, Del Giudice R, Bond PJ, Schmidtchen A. Concentrationand $\mathrm{pH}$-dependent oligomerization of the thrombin-derived C-terminal peptide TCP25. Biomolecules. 2020;10(11):1572.

42 Trabulo S, Cardoso AL, Mano M, De Lima MC. Cell-penetrating peptides-mechanisms of cellular uptake and generation of delivery systems. Pharmaceuticals. 2010;3(4):961-93.

43 Hotchkiss RS, Karl IE. The pathophysiology and treatment of sepsis. N Engl J Med. 2003; 348(2):138-50.

44 Rittirsch D, Flierl MA, Ward PA. Harmful molecular mechanisms in sepsis. Nat Rev Immunol. 2008;8(10):776-87.

45 de Jong HK, van der Poll T, Wiersinga WJ. The systemic pro-inflammatory response in sepsis. J Innate Immun. 2010;2(5):422-30.

46 Puthia M, Butrym M, Petrlova J, Stromdahl AC, Andersson MA, Kjellstrom S, et al. A dual-action peptide-containing hydrogel targets wound infection and inflammation. Sci Transl Med. 2020;12(524):eaax6601. 